\title{
THE ROLE OF VARICOCELE REPAIR IN THE NEW ERA OF ASSISTED REPRODUCTIVE TECHNOLOGY
}

\author{
Marcello Cocuzza, ${ }^{\mathrm{I}}$ Mariana Amora Cocuzza, ${ }^{\mathrm{II}}$ Frances Monette Papa \\ Bragais, "II Ashok Agarwal ${ }^{\mathrm{III}}$
}

doi: 10.1590/S1807-59322008000300018

Cocuzza M, Cocuzza MA, Bragais FMP, Agarwal A. The role of varicocele repair in the new era of assisted reproductive technology. Clinics. 2008;63:395-404.

Infertility affects $10-15 \%$ of couples who are trying to conceive, and half of the cases are due to male infertility. Intracytoplasmic sperm injection is increasingly being used to overcome multiple sperm deficiencies. Due to its effectiveness, some have proposed ICSI as a solution for all cases of male infertility, regardless of the cause. Hence, even men with potentially treatable causes of infertility have sought the aid of assisted reproductive technology, rather than undergo specific therapies to treat their infertility. Varicoceles are the most frequent physical finding in infertile men; indeed, they may be responsible for nearly one-third of cases of male infertility. Varicocele management, however, has always been a controversial issue because very few randomized, controlled studies have been performed to examine varicocelectomy as an infertility treatment.

Significant evidence suggests that varicoceles have a harmful effect on the testis and that varicocelectomy can not only prevent progressive decline in testicular function but also reverse the damage. However, the degree to which varicocele repair improves pregnancy rates and the success of assisted reproductive technology remains controversial.

KEYWORDS: Varicocele. Varicocelectomy. Male infertility. Seminal parameters. Assisted reproductive techniques.

\section{INTRODUCTION}

Varicocele is a condition that involves the dilatation of the pampiniform plexus, which drains blood from the testicles. Normally, reverse blood flow is prevented by small, one-way valves. Defects in these valves or compression of the veins by adjacent structures can cause vessel dilatation. The incidence of clinical varicocele in the general population is approximately $15 \%$, but it was initially difficult to demonstrate any association of varicocele with abnormal semen parameters or decreased fertility in these populations. ${ }^{1,2}$ Studies of unselected fertile men with and

\footnotetext{
I Department of Urology, Faculdade de Medicina, Universidade de São Paulo - São Paulo/SP, Brazil.

II Department of Gynecology, Faculdade de Medicina, Universidade de São Paulo - São Paulo/SP, Brazil.

III Glickman Urological and Kidney Institute, Cleveland Clinic Foundation - Cleveland, OH, USA. mcocuzza@uol.com.br

Received for publication on January 25, 2008

Accepted for publication on February 07, 2008
}

without varicocele have shown no significant differences between standard semen parameters, such as sperm count, motility, and morphology. 3,4

Over the past decade, however, several studies have established an association between the presence of varicocele and abnormal semen parameters in infertile patients. In 1965, MacLeod first reported that sperm in the majority of semen samples obtained from infertile men with varicocele were present at a lower count, showed decreased motility, and more frequently had abnormal morphologies compared to sperm from fertile men. ${ }^{5}$ A study of varicocele conducted by the World Health Organization (WHO) reported a prevalence of $25.4 \%$ in infertile men with abnormal semen; the study noted that it was accompanied by decreased testicular volume, lower total sperm count, and a decline in Leydig cell function.

Varicocele has been implicated as a cause in 35-50\% of patients with primary infertility and up to $81 \%$ of men with secondary infertility. ${ }^{6,7}$ The surprisingly high incidence in secondary infertility suggests that varicoceles cause progressive decline in testicular function over time. Although 
varicocele repair is widely used as a treatment for male infertility, its efficacy has been a subject of intense debate for nearly 50 years. Although the ultimate goal of treating male factor infertility is to increase the pregnancy rate, varicocelectomy also seeks to maximize a couple's fertility potential by improving sperm quality or avoiding a decline in testicular function.

The following review discusses current concepts in varicocele and summarizes the leading theories on the mechanisms of varicocele-induced testicular damage. It reviews existing literature on the efficacy of varicocelectomy for treating infertility. The current indications for varicocelectomy and management of varicocele are also discussed for azoospermic patients and infertile couples involving older women. Finally, apart from the relationship between varicocele and semen quality, the authors critically review the cost-effectiveness of varicocele treatment compared to assisted reproductive techniques.

\section{CURRENT UNDERSTANDING OF THE PATHOPHYSIOLOGY OF VARICOCELES}

Varicocele formation is likely to have a multifactorial origin, and various mechanisms have been proposed to explain infertility in men with varicocele. The precise etiology remains unproven, but mechanisms suggested include hypoxia and stasis, testicular venous hypertension, elevated testicular temperature, increase in spermatic vein catecholamines, and increased oxidative stress. ${ }^{8}$

While its exact origins remain unknown, the basic pathology of varicocele is clear: it involves venous dilatation of internal spermatic veins and pampiniform plexus. Primary varicoceles involve defective valves, while secondary varicoceles result from venous compression by outside factors such as retroperitoneal tumors. Microscopic evaluation of spermatic vein fragments has revealed alterations in the longitudinal muscle layers, in addition to a decrease in the number of nerve elements and "vasa vasorum" in the vessel wall. ${ }^{9}$ These findings suggest a defective contractile mechanism of blood transport through the pampiniform plexus. In addition, hydrostatic pressure has been shown to increase by as much as five-fold in vasography studies of the spermatic veins. ${ }^{10}$ This reverses the pressure gradient, thereby leading to a hypoxic state. ${ }^{10,11}$

Biopsies of varicocele-affected testes show a decrease in E-cadherin and alpha-catenin at the Sertoli-Sertoli junction, and subsequent disruption of the blood-testis barrier, which can contribute to defects in sperm production. ${ }^{12}$ In addition, atomic force microscopy reveals structural and morphological alterations in the sperm neckpiece and flagella, as well as changes in head dimensions. ${ }^{13}$
Oxidative stress due to an excess of reactive oxygen species (ROS), is now recognized as a major factor in infertility. ${ }^{14-16}$ Normally, the body contains a minimum amount of ROS remain, since they are needed for regulating normal sperm functions such as sperm capacitation, the acrosome reaction, and sperm-oocyte fusion. ${ }^{17}$ However, in $25-40 \%$ of infertile men, the semen has been found to produce excessive amounts of ROS. ${ }^{18,19}$ Men whose semen contains elevated ROS levels may have decreased fertility for both in vitro and in vivo procedures, and there may be negative effects on embryo development ${ }^{20,21}$. The association between semen ROS levels and varicocele has been well documented over the last few years. ${ }^{22-25}$ According to a new meta-analysis from our center, oxidative stress parameters are significantly increased in varicocele patients compared with normal sperm donors. ${ }^{26}$ Mitropoulos et al. ${ }^{24}$ evaluated peripheral blood samples in subfertile men with varicocele and compared them with blood samples from the dilated varicocele vein before ligation. The authors found elevated oxidative stress due to the release of nitric oxide synthase and xanthine oxidase within the dilated spermatic vein. This led to dramatic increases in the levels of nitric oxide, peroxynitrite, and S-nitrosothiols, all of which are biologically active. They suggested that peroxynitrite production from the reaction of nitric oxide and superoxide might be responsible for impaired sperm function in patients with varicocele. Allamaneni et al. ${ }^{27}$ reported that semen ROS levels correlated positively with varicocele grade. In addition, the authors showed that men with varicocele grade II or III had significantly higher semen ROS levels than men with varicocele grade I. Similarly, Koksal et al. ${ }^{28}$ evaluated levels of malondialdehyde in testicular biopsy specimens and found significantly higher levels of malondialdehyde in infertile men with grade III varicocele compared to men with grade I or II varicocele. These findings indicate that increased oxidative stress is associated with more severe varicocele. Surgical varicocelectomy has recently been shown to reduce seminal oxidative stress in infertile men. ${ }^{29-31}$

Elevated production of ROS in the reproductive tract disrupts not only the fluidity of the sperm plasma membrane, but also the integrity of DNA in the sperm nucleus. Infertile men with varicoceles have high levels of spermatozoal DNA damage. ${ }^{32}$ For example, Chen et al. ${ }^{33}$ reported that patients with varicocele showed increased levels of 8-hydroxy-2'deoxyguanosine, an indicator of oxidative DNA damage. Excessive levels of DNA damage have been associated with a decrease in several fertility indices, including fertilization rate, embryo cleavage rate, implantation rate, pregnancy rate, and live birth rate. DNA damage can have significant clinical implications because in vitro fertilization using spermatozoa containing damaged DNA may lead to paternal transmission of defective genetic material with adverse consequences for 
embryonic development. This damage may be reversible: Zini and Libman recently reported that infertile men showed improved sperm DNA integrity six months after varicocele repair. ${ }^{34}$ These studies may help us understand the pathophysiology of varicoceles, and possibly lead to the development of improved diagnostic tools.

\section{WHO BENEFITS FROM VARICOCELE REPAIR?}

Varicoceles are typically diagnosed when the patient is standing, preferably in a warm room. The scrotum should be manually palpated, and it is important to have the patient perform a Valsalva maneuver during the examination. Classically, varicoceles are graded according to the following criteria: grade I refers to palpable vein dilatation only during the Valsalva maneuver; grade II refers to palpable vein dilatation when the patient is standing; and grade III refers to venous dilatation visible through the scrotal skin. Subclinical varicoceles are those not detectable by physical examination but detectable by Doppler ultrasonography. Approximately $90 \%$ of varicoceles are unilateral on the left side. Less frequently, bilateral varicoceles are present, while right-sided varicoceles are rare and should raise suspicions of a retroperitoneal mass that is compromising venous return from the right testis. ${ }^{35,36}$

The Practice Committee of the American Society for Reproductive Medicine recently published recommendations for the evaluation and treatment of varicoceles. ${ }^{37}$ This report was previously published as a peer-reviewed consensus jointly with The Male Infertility Best Practice Policy Committee of the American Urological Association. The committee concluded that varicocelectomy should be offered to the male partner in couples attempting to conceive only when all of the following conditions were present: a palpable varicocele, documented couple infertility, a female partner with normal fertility or potentially correctable infertility, and a male partner with one or more abnormal semen parameters or test results showing abnormal sperm function. In addition, an adult male presenting with palpable varicocele and abnormal semen analyses is a candidate for varicocele repair even if he is not currently attempting to conceive but has a desire for future fertility. Varicocele treatment for infertility is not indicated in patients with normal semen parameters, even those presenting with testicular atrophy. The use of testicular volume as a predictor of fertility in patients with varicocele is still controversial. Pinto et al. ${ }^{38}$ showed that testicular size was not a predictor of fertility potential in patients with varicocele. On the other hand, testicular hypotrophy is the most widely accepted indication for correcting adolescent varicocele. Mandatory varicocele repair for all adolescents would be inappropriate, since it is not cost-effective, and fertility is not necessarily affected by varicoceles. In general, adolescent varicoceles are associated with testicular volume loss, endocrine abnormalities, and abnormal seminal parameters. ${ }^{39}$ Varicocele repair should be offered to adolescents presenting palpable varicocele and ipsilateral testicular growth retardation greater than $2 \mathrm{ml}$ or two standard deviations from the mean of the normal testicular growth curve. Those presenting with normal ipsilateral testicular size, however, should be offered follow-up monitoring with annual measurement of testicular size or semen analyses. ${ }^{37}$ In addition, because of the complexity to evaluate testicular growth retardation in adolescents presenting with bilateral varicocele or a solitary testis, varicocelectomy should be considered in such cases. The option of seminal analysis may be discussed for older adolescents in an effort to facilitate the decision of whether to treat, although few studies have determined normal seminal parameters in this population, presumably because of ethical concerns associated with the procurement of semen specimens in young boys. ${ }^{40,41}$ In cases of abnormal seminal parameters associated with high grade varicocele, surgery should be offered, even when testicular size is normal. The current guidelines for varicocele management are summarized in Figure 1.

Unfortunately, the decision to use varicocele repair as an infertility treatment is usually less clear, and a variety of important points must also be considered, including the female partner's age, the period during which the couple has failed to conceive, and poor semen quality. Another important point is to explain to the couple that pregnancy is not immediately achieved after varicocele repair. The mean time for semen improvement and spontaneous pregnancy after surgery is approximately five and seven months, respectively. ${ }^{42,43}$ However, the etiology underlying infertility is especially uncertain in men whose seminal parameters do not significantly improve or do not achieve pregnancy following varicocele surgery. A key to resolving this issue is to evaluate variables of favorable prognosis in order to identify patients who may benefit from treatment.

Current evidence supports the idea that varicocele size does matter and that repair of large varicoceles is more likely to improve seminal parameters than repair of smaller varicoceles ${ }^{44}$ In fact, varicocele treatment is not indicated in patients with subclinical varicoceles, since the improvements in seminal parameters or pregnancy rate are identical to those obtained by treatment with clomiphene citrate. ${ }^{45}$

Patients with higher sperm counts prior to repair show significantly greater absolute improvement in semen parameters than those with more severe oligospermia. ${ }^{46} \mathrm{In}$ addition, men who achieved a postoperative total motile sperm count greater than 20 million were also more likely to achieve pregnancy using less invasive techniques, namely spontaneous pregnancy or intrauterine insemination. ${ }^{47}$ 


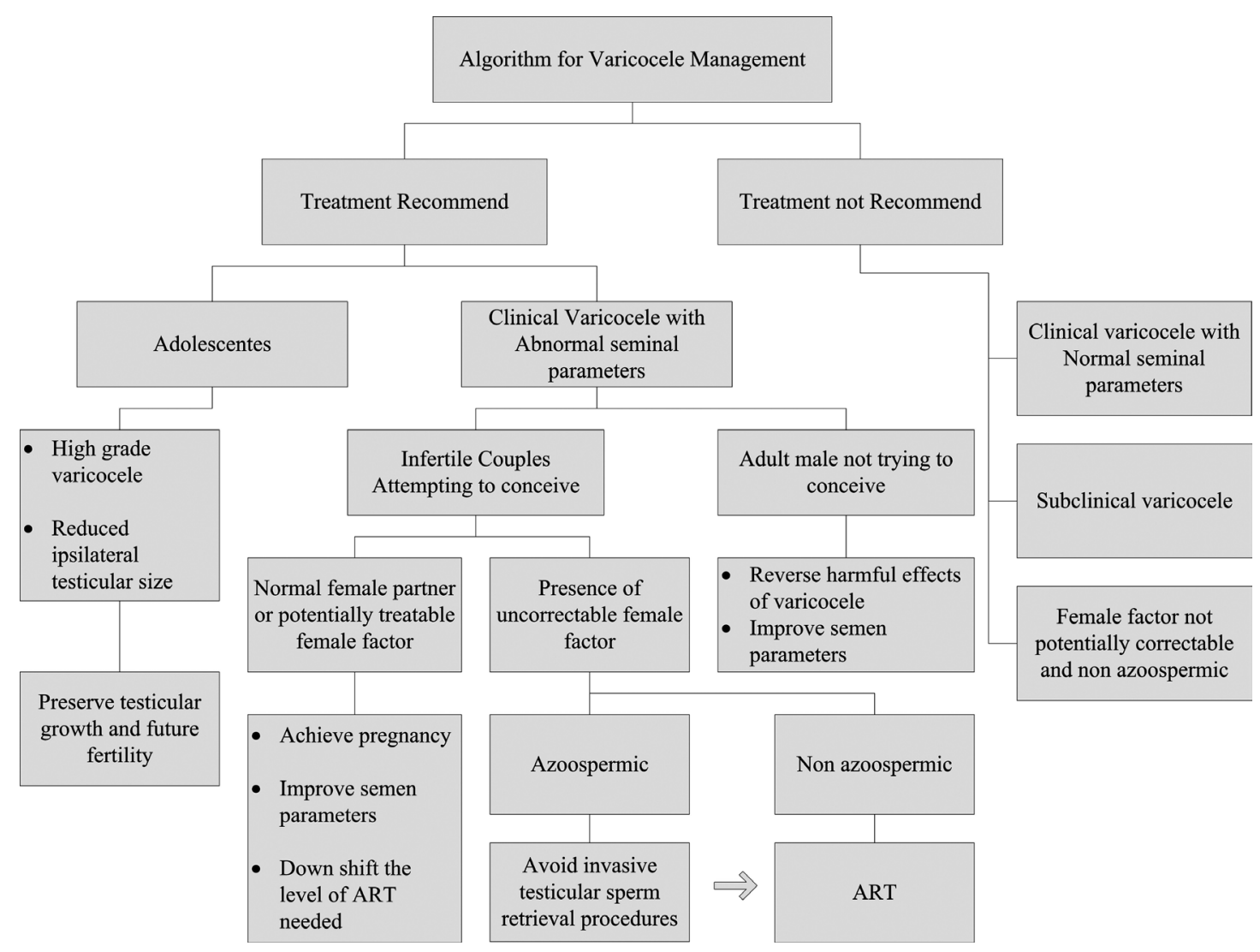

Figure 1 - Algorithm for Varicocele Management.

Patients presenting with sperm motility of $60 \%$ or more before varicocele repair had better pregnancy rates after surgery. On the other hand, reduced presurgical testicular volume and elevated FSH concentration predict negative post-surgical outcomes. ${ }^{48,49}$

The Y chromosome plays a critical role in the control of spermatogenesis; therefore, $\mathrm{Y}$ chromosome microdeletions are another factor associated with little or no improvement of seminal parameters following varicocele ligation. ${ }^{50}$ The incidence of $\mathrm{Y}$ chromosome microdeletion in infertile men with varicocele is approximately $3 \% .{ }^{51}$ As a result, men with poor seminal parameters and $\mathrm{Y}$ chromosome microdeletions may have an incidental varicocele, surgical repair of which is unlikely to improve fertility. ${ }^{8}$

The predictors of varicocele repair outcome are summarized in Table 1. These prognostic indicators may help identify those men with better prognosis for varicocelectomy or help to select those couples more likely to be initial candidates for ART.

\section{CHOOSING VARICOCELECTOMY OR ASSISTED REPRODUCTIVE TECHNOLOGY}

The advent of ICSI has transformed the role of the
Table 1 - Predictors of varicocele repair outcomes in infertile patients

\begin{tabular}{ll}
\hline Good prognosis & Poor prognosis \\
\hline High grade varicocele (grade III) & Subclinical varicocele \\
Normal serum FSH $*$ & $\begin{array}{l}\text { Presence of Y chromosome } \\
\text { microdeletion }\end{array}$ \\
Total motility $>60 \% *$ & Testicular Atrophy $*$ \\
Total motile sperm & Total motile sperm \\
count $>5 \times 10^{6} *$ & count $<20 \times 10^{6} * *$ \\
\hline
\end{tabular}

Notes: FSH, Follicle-stimulating hormone. * Before varicocele repair. ** After varicocele repair

andrologist. Relative pregnancy rates achieved by ICSI have led to a troubling decrease in efforts to correctly diagnose the causes of infertility.

Although ART provides infertile families with the possibility of pregnancy, potential medical risks including multiple-gestation pregnancies, as well as their associated costs, cannot be ignored. Couples considering ART should be aware of the risks associated with these procedures.

As mentioned, medical risks including multiplegestations and ovarian hyperstimulation must be considered. In vitro fertilization leads to mild ovarian hyperstimulation 
in up to $20 \%$ of women undergoing IVF and to moderate ovarian hyperstimulation in 5\% of these patients. Although the prevalence of severe ovarian hyperstimulation is less than $1 \%$, it still carries the risk of a potentially fatal outcome. ${ }^{52}$ Overall, the risk for twin gestation is $30-35 \%$, and the risk for gestation of triplets or higher is $5-10 \% .{ }^{53}$ Multiple-gestations births are associated with both increased infant mortality and morbidity. ${ }^{54,55}$ Although an extensive review of the safety considerations in ART is beyond the scope of this article, safety factors may play an important role in deciding between varicocele repair or IVF/ICSI.

In addition to safety issues, the cost-effectiveness of procedures for infertile couples with male varicocele should also be considered. Is ICSI or varicocele repair a better choice? Schlegel first reported a comparison of ICSI and varicocele repair using an analysis of "cost per delivery". He concluded that primary treatment with varicocelectomy was the more cost-effective approach, rather than sperm retrieval/ICSI, since varicocelectomy provided comparable delivery rates for a less expensive fee. ${ }^{56}$ Total hospital delivery costs as well as costs attributable to multiple gestations and complications were analyzed. The average delivery rate reported in the U.S. after one ICSI attempt was $28 \%$ compared to $30 \%$ after varicocele repair. The average cost per delivery for varicocelectomy was $\$ 26,268$, whereas it was estimated at $\$ 89,091$ for ICSI.

Meng et al. ${ }^{57}$ also compared the cost of pregnancy following varicocelectomy to pregnancy through ART in patients with varicocele, but these researchers used a decision analysis model. Decision models rely on predefined assumptions, and the models serve to estimate procedural outcomes when several treatment options are available. Like Schlegel, these authors also concluded that initial varicocele repair was more cost-effective than ART treatment for infertile couples.

While ICSI provides a viable alternative for the treatment of infertile couples with varicocele, current evidence suggests that varicocele treatment is the more cost-effective therapy for infertility.

\section{HOW VARICOCELECTOMY INTERFERES IN THE OUTCOMES OF ASSISTED REPRODUCTIVE TECHNOLOGY}

For couples with male factor infertility associated with varicocele, treatment options include varicocele repair, intrauterine insemination (IUI), and in vitro fertilization/ intracytoplasmic sperm injection (IVF/ICSI). Multiple factors influence the couple's choice of method. Varicocele repair may provide a permanent cure for infertility, since it can reverse the pathologic conditions causing infertility. An effort to maximize a couple's fertility by improving sperm quality or avoiding a decline in testicular function is an important objective of treatment, especially in couples desiring more than one child. Conversely, ART procedures must be performed each time that a couple attempts to get pregnant. Those opting to forgo varicocele treatment may experience a progressive decline in semen parameters, further compromising their future fertility. ${ }^{6,7}$ Additional factors to consider include the unknown long-term health effects of ART procedures and the age of the female partner.

It is unusual for varicocele repair to be indicated when IVF is already required for treating female infertility. Nevertheless, under certain circumstances, varicocele treatment should be considered prior to ART, even in the presence of female infertility. Varicocele repair has been suggested as a way to restore sperm to the ejaculate in men with non-obstructive azoospermia. ${ }^{58,59}$ Following such restoration, although the sperm count is minimal, it still may allow IVF/ICSI without the need for testicular sperm aspiration or extraction.

Even though spontaneous pregnancy remains the ultimate standard for evaluating the success of varicocele treatment, studies have shown other benefits of surgical repair. ${ }^{60}$ Varicocele repair may allow some couples to proceed with IUI prior to proceed with more advanced assisted reproductive techniques. Recent studies have shown that varicocelectomy significantly increases pregnancy and live birth rates after intrauterine insemination (IUI), even when seminal parameters do not improveme. ${ }^{60,61}$ These findings suggest that the increase in pregnancy rates following varicocelectomy may be due to functional factors not tested during standard semen analysis, such as seminal oxidative stress and integrity of sperm DNA. ${ }^{60}$ Cayan et al. ${ }^{62}$ reported that varicocelectomy has significant potential not only to obviate the need for ART, but also to minimize the level of ART needed to bypass male infertility.

\section{VARICOCELE IN AZOOSPERMIC MEN}

Azoospermia is defined as the complete absence of sperm from the ejaculate and is present in approximately $1 \%$ of all men and up to $15 \%$ of infertile men. ${ }^{63,64}$ Testicular disorders leading to azoospermia are generally irreversible and are classified as non-obstructive azoospermia. The prevalence of varicocele in men with azoospermia is estimated to range between 5\% and 10\%.58,59,65 In 1955 Tulloch reported that varicocele repair in an azoospermic patient restored spermatogenesis and led to successful pregnancy, and this announcement renewed interest in varicocele treatment. ${ }^{66}$ Although spontaneous pregnancy is rare, motile sperm are 
found in the ejaculate of azoospermic men in $21-55 \%$ of cases following varicocele repair. ${ }^{58,59,67,68}$ Varicocele repair in this population may obviate the need for subsequent testicular sperm retrieval procedures, since sperm can be provided via ejaculation.

Even though varicocele repair can improve spermatogenesis in up to $50 \%$ of azoospermic patients, assisted reproductive techniques will be necessary for the majority of these couples to initiate pregnancy. ${ }^{69}$ However, the rates of successful fertilization and ICSI are higher when fresh, motile, ejaculated sperm are used compared to sperm provided by testicular biopsy or microsurgical testicular sperm extraction. ${ }^{70,71}$

Moreover, although azoospermic patients may show improved spermatogenesis after varicocelectomy, a gradual decline in spermatogenesis and return to azoospermia have been reported in up to $55.5 \%$ of patients one year after surgery. ${ }^{69}$ These patients may experience intermittent sperm production; in fact, the effects of varicocele repair may be only temporary, resulting in the induction of spermatogenesis for a short period of time. Since these patients may not be able to maintain spermatogenesis, semen cryopreservation is strongly recommended following initial improvement after surgery.

Microdeletions of the $\mathrm{Y}$ chromosome can be detected in up to $18 \%$ of azoospermic men. ${ }^{64}$ Karyotype and $\mathrm{Y}$ chromosome mapping are crucial in the evaluation of men with varicocele and azoospermia. These patients should be aware of chromosomal abnormalities so that they can obtain genetic counseling in order to quantify their risk of transmitting them to their offspring. Thus, accurate diagnosis of the etiology of azoospermia is crucial prior to the initiating appropriate treatment.

\section{VARICOCELECTOMY IN INFERTILE COUPLES WITH OLDER WOMEN}

Although advanced maternal age may be an important cause of a couple's infertility, the true influence of advanced female age on the outcome of varicocelectomy is poorly understood. ${ }^{72}$ Nevertheless, studies clearly show an agerelated decline in female fertility, which can be attributed to a number of potential causes, including changes in oocyte quality, the frequency and efficiency of ovulation, sexual function, and uterine health. ${ }^{73}$

Because the average interval between varicocele repair and pregnancy is usually longer than 6 months, couples may prefer ICSI when the female partner is older than 37. However, the success of ICSI decreases dramatically in woman older than 37 years. ${ }^{74}$ Nieschlag et al. ${ }^{75}$ were the first to observe that female age is a considerable predictor of pregnancy outcome following varicocele repair. The authors reported a significant difference in the woman's age at conception: the 34 females achieving pregnancy were $28.8 \pm 0.6$ years old, while the 91 non-pregnant females were $31.2 \pm 0.3$ years old $(\mathrm{p}<0.05)$.

O'Brien et al. evaluated the outcomes of two cohorts of infertile men with varicocele who had female partners at least 35 years old $(n=202)$. One group chose to receive microsurgical varicocelectomy, and the other chose observation. Sperm count and total motility significantly increased after varicocele repair $(\mathrm{p}<0.05)$. By an average of 30 months after the surgery, $35 \%$ of couples in the surgical group had achieved spontaneous pregnancy, and an additional $6 \%$ achieved pregnancy via ART. (Of the couples in the surgical group, 20\% attempted ART.) In the nonsurgical group, 25\% achieved spontaneous pregnancy, and an additional $16 \%$ achieved pregnancy with ART. (Of this group, 40\% attempted ART.) This study on the outcomes of infertile men with varicocele and advanced female age suggests that surgical and nonsurgical approaches lead to similar pregnancy rates: the combined assisted and unassisted pregnancy rates were approximately $40 \%$. These findings suggest that varicocelectomy is an acceptable option for couples with older women, but that the decision-making process should take into account other female factors, including health, ART-related complicationsand cost. ${ }^{76}$

\section{HOW CAN VARICOCELE BE TREATED?}

Two approaches are currently used in varicocele repair: surgery and percutaneous radiographic embolization. Neither of these methods has proven more effective at improving fertility than the other; however, the two methods do differ in their recurrence rates and potential complications. ${ }^{77}$

Percutaneous embolization treatment is successfully carried out in only approximately $90 \%$ of attempts; therefore, a considerable number of patients will ultimately require another procedure. ${ }^{78}$ Although this approach is associated with quicker recovery and less pain than standard surgery, it requires interventional radiologic expertise. Complications include vascular perforation, coil migration, and thrombosis of the pampiniform plexus. ${ }^{79,80}$ This technique may be useful for managing varicoceles that persist or recur following traditional surgery.

Surgical repair of a varicocele can be performed using various open surgical methods, including retroperitoneal, inguinal, and subinguinal approaches, as well as laparoscopic techniques. Although the laparoscopic approach has been used for varicocele repair, the risk of major intraperitoneal complications and the high cost of the equipment have called into question the cost-benefit of this approach. ${ }^{81}$ 
The inguinal approach has lower recurrence rates and allows the lymphatic vessels to be preserved. ${ }^{82}$ Because this technique involves opening the inguinal canal, however, patients must wait longer after the operation before returning to work. The subinguinal approach follows the same principals as the inguinal approach, but is performed through an incision below the external inguinal ring. Because this technique obviates the need to open the aponeurosis of the external oblique, it causes less pain. Most experts prefer the microsurgical subinguinal or inguinal varicocelectomy. The use of an operating microscope providing magnification up to $25 \mathrm{x}$ allows preservation of the testicular artery as well as the lymphatic vessels. This translates to a lower incidence of hydrocele and reduced risk of persistence or varicocele recurrence ${ }^{83}$ Complications following varicocelectomy are rare. Hydrocele is the most common complication after a non-microscopic varicocelectomy, and it occurs in approximately $7 \%$ of cases ${ }^{81}$ However, the use of a magnifying microscope to identify and preserve lymphatic vessels can virtually eliminate the incidence of hydrocele following varicocelectomy. ${ }^{83,84}$

\section{RESULTS OF VARICOCELE REPAIR IN THE AGE OF EVIDENCE-BASED MEDICINE}

Although many have labeled varicocele the most surgically correctible cause of male infertility, not all experts agree. Varicocelectomy studies have reported significant improvements in one or more semen parameters in approximately $65 \%$ of treated men. ${ }^{46}$ However, in this age of evidence-based medicine, it is interesting that few randomized, controlled studies have been performed to evaluate patient fertility after varicocelectomy. The reviews concerning the efficacy of varicocelectomy in subfertile couples differ widely in quality and breadth, and several include studies using suboptimal methodologies. ${ }^{85}$ Comparing these reported trials is confounded by substantial differences in important factors such as varicocele size, infertility cause, seminal parameter criteria for inclusion in the study, concurrent female fertility factors, and different follow-up periods after varicocelectomy. ${ }^{86}$ Therefore, it is difficult to draw clear conclusions about the impact of varicocele repair on fertility.

A systematic review of varicocele repair as a treatment for male subfertility concluded that surgical or radiological approaches does not seem to be an effective treatment. ${ }^{87}$ However, this meta-analysis was strongly criticized for including patients with normal seminal parameters as well as subclinical varicoceles, which are not currently considered indications for varicocelectomy. ${ }^{85}$

So far only two randomized, prospective, controlled studies have addressed fertility outcomes in subfertile patients with clinical varicocele, abnormal seminal parameters, and no female factors. The first study compared interventional treatment (e.g. surgical repair or angiographic embolization) with counseling only for infertile couples. ${ }^{75}$ Although semen parameters improved significantly in the treated group, pregnancy rates did not differ between the two groups. However, half of the varicoceles in this study were small (grade I), and approximately $25 \%$ were treated with embolization rather than surgical ligation. Moreover, the study did not include microsurgical artery-sparing ligation techniques, and pregnancy rates were lower than reported by other authors. The second study uses the best design so far to determine the benefits of varicocele surgical repair; the authors use a cross-over design of surgery compared with observation. ${ }^{88}$ They observed a significant pregnancy rate improvement following varicocelectomy. Although both studies reported improvements in seminal quality after varicocele repair, the pregnancy outcomes were different between the two, so they failed to resolve the uncertainty concerning the effect of varicocele treatment on fertility.

Recently our center has tried to address this controversy by conducting two meta-analyses and including only randomized, controlled trials and observational studies. The first examined the effect of varicocelectomy on semen parameters. ${ }^{89}$ This analysis demonstrated that sperm concentration increased by $9.71 \times 10 \% \mathrm{~mL}$ [95\% confidence interval (CI), 7.34-12.08, $P<0.00001$ ), total motility increased by $9.92 \%$ (95\% CI, 4.90-14.95, $\mathrm{P}=0.0001)$, and sperm morphology according to WHO standards increased by $3.16 \%$ (95\% CI, 0.72-5.60, $P=0.01$ ) after varicocelectomy. The authors concluded that surgical varicocelectomy was an effective treatment for improving semen parameters of infertile males with a clinically palpable varicocele. The second meta-analysis evaluated pregnancy rates for infertile couples in which the male partner had abnormal semen parameters and clinical varicocele..$^{90}$ Based on data from the current literature and contrary to previous meta-analyses, our study suggested that varicocelectomy did indeed improve fertility by increasing the likelihood of spontaneous pregnancy in female partners. The odds of spontaneous pregnancy after surgical varicocelectomy, compared to no medical treatment for palpable varicocele, were 2.87 (95\% CI, 1.33-6.20, $p=0.007$ ). The number needed to treat was 5.7 (95\% CI, 4.1-9.5). These results further support the idea that the improvement in semen parameters following varicocelectomy may help infertile couples achieve pregnancy spontaneously or through the use of less invasive and inexpensive techniques, such as intrauterine insemination. 


\section{CONCLUSION}

Varicocele remains the most common clinical finding in infertile males and is often the only identifiable cause in infertile couples. Although the exact pathophysiology remains unknown, there is convincing evidence that varicoceles have an increasingly harmful effect on testes over time, resulting in the decline of seminal parameters. Current data suggest that varicocele repair is successful in reversing the harmful effects of varicocele on testicular function and in improving seminal parameters. However, identifying infertile men with varicocele who will most benefit from varicocele ligation remains a challenge for andrologists.

The use of assisted reproductive techniques may lead rapidly to pregnancy, but the associated cost, health risks, and invasiveness of the procedures on healthy female partners make this treatment option less appealing. On the other hand, varicocele repair may provide a permanent cure for infertility and maximize a couple's fertility, which is particularly important for couples desiring more than one child.

The efficacy of varicocele treatment for increasing the pregnancy rate has remained controversial over the last decade because of the large number of poorly designed and uncontrolled studies. Nevertheless, current evidence supports the contention that varicocele treatment should be considered an initial choice for certain infertile couples because of its greater cost-effectiveness and lower surgery-related risks compared to ART.

Although the ultimate desired outcome for infertile couples is pregnancy, varicocele repair can still be considered successful if the couple fails to conceive after the surgery. The repair can improved seminal quality and thereby obviate, or at least reduce, the need for assisted reproductive techniques. Further carefully randomized, controlled trials are needed for more precise assessments of the impact of varicocelectomy on fertility outcomes.

\section{REFERENCES}

1. Thomason AM, Fariss BL. The prevalence of varicoceles in a group of healthy young men. Mil Med. 1979;144:181-2.

2. Lund L, Larsen SB. A follow-up study of semen quality and fertility in men with varicocele testis and in control subjects. British journal of urology. 1998;82:682-6.

3. Lipshultz LI, Corriere JN, Jr. Progressive testicular atrophy in the varicocele patient. The Journal of urology. 1977;117:175-6.

4. Fariss BL, Fenner DK, Plymate SR, Brannen GE, Jacob WH, Thomason AM. Seminal characteristics in the presence of a varicocele as compared with those of expectant fathers and prevasectomy men. Fertility and sterility. 1981;35:325-7.

5. MacLeod J. Seminal cytology in the presence of varicocele. Fertility and sterility. 1965;16:735-57.

6. Gorelick JI, Goldstein M. Loss of fertility in men with varicocele. Fertility and sterility. 1993;59:613-6.

7. Witt MA, Lipshultz LI. Varicocele: a progressive or static lesion? Urology. 1993;42:541-3.

8. Marmar JL. The pathophysiology of varicoceles in the light of current molecular and genetic information. Hum Reprod Update. 2001;7:461-72.

9. Tilki D, Kilic E, Tauber R, Pfeiffer D, Stief CG, Tauber R, et al. The complex structure of the smooth muscle layer of spermatic veins and its potential role in the development of varicocele testis. Eur Urol. 2007;51:1402-9; discussion 10.

10. Gat Y, Gornish M, Navon U, Chakraborty J, Bachar GN, Ben-Shlomo I. Right varicocele and hypoxia, crucial factors in male infertility: fluid mechanics analysis of the impaired testicular drainage system. Reprod Biomed Online. 2006;13:510-5.

11. Naughton CK, Nangia AK, Agarwal A. Pathophysiology of varicoceles in male infertility. Hum Reprod Update. 2001;7:473-81.
12. Koksal IT, Ishak Y, Usta M, Danisman A, Guntekin E, Bassorgun IC, et al. Varicocele-induced testicular dysfunction may be associated with disruption of blood-testis barrier. Arch Androl. 2007;53:43-8.

13. Joshi NV, Medina H, Osuna JA. Ultrastructural pathology of varicocele spermatozoa by using atomic force microscopy (AFM). Arch Androl. 2001;47:143-52.

14. Said TM, Agarwal A, Sharma RK, Thomas AJ, Jr., Sikka SC. Impact of sperm morphology on DNA damage caused by oxidative stress induced by beta-nicotinamide adenine dinucleotide phosphate. Fertility and sterility. 2005;83(1):95-103.

15. Agarwal A, Ikemoto I, Loughlin KR. Relationship of sperm parameters with levels of reactive oxygen species in semen specimens. The Journal of urology. 1994;152:107-10.

16. de Lamirande E, Gagnon C. Reactive oxygen species and human spermatozoa. II. Depletion of adenosine triphosphate plays an important role in the inhibition of sperm motility. J Androl. 1992;13:379-86.

17. Sharma RK, Agarwal A. Role of reactive oxygen species in male infertility. Urology. 1996;48:835-50.

18. de Lamirande E, Gagnon C. Impact of reactive oxygen species on spermatozoa: a balancing act between beneficial and detrimental effects. Hum Reprod. 1995;10 Suppl 1:15-21.

19. Padron OF, Brackett NL, Sharma RK, Lynne CM, Thomas AJ, Jr., Agarwal A. Seminal reactive oxygen species and sperm motility and morphology in men with spinal cord injury. Fertility and sterility. 1997;67:1115-20.

20. Aitken RJ, Irvine DS, Wu FC. Prospective analysis of sperm-oocyte fusion and reactive oxygen species generation as criteria for the diagnosis of infertility. Am J Obstet Gynecol. 1991;164:542-51.

21. Griveau JF, Le Lannou D. Reactive oxygen species and human spermatozoa: physiology and pathology. Int J Androl. 1997;20:61-9. 
22. Hendin BN, Kolettis PN, Sharma RK, Thomas AJ, Jr., Agarwal A. Varicocele is associated with elevated spermatozoal reactive oxygen species production and diminished seminal plasma antioxidant capacity. The Journal of urology. 1999;161:1831-4.

23. Romeo C, Ientile R, Santoro G, Impellizzeri P, Turiaco N, Impala P, et al. Nitric oxide production is increased in the spermatic veins of adolescents with left idiophatic varicocele. Journal of pediatric surgery. 2001;36:389-93.

24. Mitropoulos D, Deliconstantinos G, Zervas A, Villiotou V, Dimopoulos $\mathrm{C}$, Stavrides J. Nitric oxide synthase and xanthine oxidase activities in the spermatic vein of patients with varicocele: a potential role for nitric oxide and peroxynitrite in sperm dysfunction. The Journal of urology. 1996;156:1952-8.

25. Smith R, Kaune H, Parodi D, Madariaga M, Rios R, Morales I, et al. Increased sperm DNA damage in patients with varicocele: relationship with seminal oxidative stress. Hum Reprod. 2006;21:986-93.

26. Agarwal A, Prabakaran S, Allamaneni SS. Relationship between oxidative stress, varicocele and infertility: a meta-analysis. Reprod Biomed Online. 2006;12:630-3.

27. Allamaneni SS, Naughton CK, Sharma RK, Thomas AJ, Jr., Agarwal A. Increased seminal reactive oxygen species levels in patients with varicoceles correlate with varicocele grade but not with testis size. Fertility and sterility. 2004;82:1684-6.

28. Koksal IT, Tefekli A, Usta M, Erol H, Abbasoglu S, Kadioglu A. The role of reactive oxygen species in testicular dysfunction associated with varicocele. BJU Int. 2000;86:549-52.

29. Mostafa T, Anis TH, El-Nashar A, Imam H, Othman IA. Varicocelectomy reduces reactive oxygen species levels and increases antioxidant activity of seminal plasma from infertile men with varicocele. Int $\mathbf{J}$ Androl. 2001;24:261-5.

30. Cervellione RM, Cervato G, Zampieri N, Corroppolo M, Camoglio $\mathrm{F}$, Cestaro B, et al. Effect of varicocelectomy on the plasma oxidative stress parameters. Journal of pediatric surgery. 2006;41:403-6.

31. Shiraishi K, Naito K. Generation of 4-hydroxy-2-nonenal modified proteins in testes predicts improvement in spermatogenesis after varicocelectomy. Fertility and sterility. 2006;86:233-5.

32. Saleh RA, Agarwal A, Sharma RK, Said TM, Sikka SC, Thomas AJ, Jr. Evaluation of nuclear DNA damage in spermatozoa from infertile men with varicocele. Fertil Steril. 2003;80:1431-6.

33. Chen SS, Huang WJ, Chang LS, Wei YH. 8-hydroxy-2'-deoxyguanosine in leukocyte DNA of spermatic vein as a biomarker of oxidative stress in patients with varicocele. The Journal of urology. 2004;172(4 Pt 1):1418-21.

34. Zini A, Blumenfeld A, Libman J, Willis J. Beneficial effect of microsurgical varicocelectomy on human sperm DNA integrity. Hum Reprod. 2005;20:1018-21.

35. Dubin L, Amelar RD. Etiologic factors in 1294 consecutive cases of male infertility. Fertility and sterility. 1971;22:469-74.

36. Skoog SJ, Roberts KP, Goldstein M, Pryor JL. The adolescent varicocele: what's new with an old problem in young patients? Pediatrics. 1997;100:112-21.

37. Report on varicocele and infertility. Fertility and sterility 2006:S93-5.
38. Pinto KJ, Kroovand RL, Jarow JP. Varicocele related testicular atrophy and its predictive effect upon fertility. The Journal of urology. 1994;152(2 Pt 2):788-90.

39. Bong GW, Koo HP. The adolescent varicocele: to treat or not to treat. Urol Clin North Am. 2004;31:509-15, ix.

40. Okuyama A, Nakamura M, Namiki M, Takeyama M, Utsunomiya M, Fujioka H, et al. Surgical repair of varicocele at puberty: preventive treatment for fertility improvement. The Journal of urology. 1988;139:562-4.

41. Laven JS, Haans LC, Mali WP, te Velde ER, Wensing CJ, Eimers JM. Effects of varicocele treatment in adolescents: a randomized study. Fertility and sterility. 1992;58:756-62.

42. Colpi GM, Carmignani L, Nerva F, Piediferro G, Castiglioni F, Grugnetti $\mathrm{C}$, et al. Surgical treatment of varicocele by a subinguinal approach combined with antegrade intraoperative sclerotherapy of venous vessels. BJU Int. 2006;97:142-5.

43. Dubin L, Amelar RD. Varicocele size and results of varicocelectomy in selected subfertile men with varicocele. Fertility and sterility. 1970;21:606-9.

44. Steckel J, Dicker AP, Goldstein M. Relationship between varicocele size and response to varicocelectomy. The Journal of urology. 1993;149:769-71.

45. Unal D, Yeni E, Verit A, Karatas OF. Clomiphene citrate versus varicocelectomy in treatment of subclinical varicocele: a prospective randomized study. Int J Urol. 2001;8:227-30.

46. Schlesinger MH, Wilets IF, Nagler HM. Treatment outcome after varicocelectomy. A critical analysis. Urol Clin North Am. 1994;21:517-29.

47. Matkov TG, Zenni M, Sandlow J, Levine LA. Preoperative semen analysis as a predictor of seminal improvement following varicocelectomy. Fertility and sterility. 2001;75:63-8.

48. Marks JL, McMahon R, Lipshultz LI. Predictive parameters of successful varicocele repair. The Journal of urology. 1986;136:609-12.

49. Yoshida K, Kitahara S, Chiba K, Horiuchi S, Horimi H, Sumi S, et al. Predictive indicators of successful varicocele repair in men with infertility. International journal of fertility and women's medicine. 2000;45:279-84.

50. Cayan S, Lee D, Black LD, Reijo Pera RA, Turek PJ. Response to varicocelectomy in oligospermic men with and without defined genetic infertility. Urology. 2001;57:530-5.

51. Pryor JL, Kent-First M, Muallem A, Van Bergen AH, Nolten WE, Meisner L, et al. Microdeletions in the Y chromosome of infertile men. The New England journal of medicine. 1997;336:534-9.

52. Budev MM, Arroliga AC, Falcone T. Ovarian hyperstimulation syndrome. Critical care medicine. 2005;33(10 Suppl):S301-6.

53. Assisted reproductive technology in the United States: 1996 results generated from the American Society for Reproductive Medicine/ Society for Assisted Reproductive Technology Registry. Fertil Steril. 1999;71:798-807.

54. Callahan TL, Hall JE, Ettner SL, Christiansen CL, Greene MF, Crowley WF, Jr. The economic impact of multiple-gestation pregnancies and the contribution of assisted-reproduction techniques to their incidence. The New England journal of medicine. 1994;331 :244-9. 
55. Wilcox LS, Kiely JL, Melvin CL, Martin MC. Assisted reproductive technologies: estimates of their contribution to multiple births and newborn hospital days in the United States. Fertility and sterility. 1996;65:361-6.

56. Schlegel PN. Is assisted reproductive the optimal treatment for varicocele-associated male infertility? A cost-effectiveness analysis. Urology. 1997;49:83-90.

57. Meng MV, Greene KL, Turek PJ. Surgery or assisted reproductive? A decision analysis of treatment costs in male infertility. The Journal of urology. 2005;174:1926-31; discussion 31.

58. Matthews GJ, Matthews ED, Goldstein M. Induction of spermatogenesis and achievement of pregnancy after microsurgical varicocelectomy in men with azoospermia and severe oligoasthenospermia. Fertility and sterility. 1998;70:71-5.

59. Kim ED, Leibman BB, Grinblat DM, Lipshultz LI. Varicocele repair improves semen parameters in azoospermic men with spermatogenic failure. The Journal of urology. 1999;162(3 Pt 1):737-40.

60. Daitch JA, Bedaiwy MA, Pasqualotto EB, Hendin BN, Hallak J, Falcone $\mathrm{T}$, et al. Varicocelectomy improves intrauterine insemination success rates in men with varicocele. The Journal of urology. 2001;165:1510-3.

61. Penson DF, Paltiel AD, Krumholz HM, Palter S. The cost-effectiveness of treatment for varicocele related infertility. The Journal of urology. 2002;168:2490-4

62. Cayan S, Erdemir F, Ozbey I, Turek PJ, Kadioglu A, Tellaloglu S. Can varicocelectomy significantly change the way couples use assisted reproductive technologies? The Journal of urology. 2002;167:1749-52.

63. Jarow JP, Espeland MA, Lipshultz LI. Evaluation of the azoospermic patient. The Journal of urology. 1989;142:62-5.

64. Pagani R, Brugh VM, 3rd, Lamb DJ. Y chromosome genes and male infertility. Urol Clin North Am. 2002;29:745-53.

65. Czaplicki M, Bablok L, Janczewski Z. Varicocelectomy in patients with azoospermia. Arch Androl. 1979;3:51-5.

66. Tulloch WS. Varicocele in subfertility; results of treatment. British medical journal. 1955;2:356-8.

67. Lee JS, Park HJ, Seo JT. What is the indication of varicocelectomy in men with nonobstructive azoospermia? Urology. 2007;69:352-5.

68. Kadioglu A, Tefekli A, Cayan S, Kandirali E, Erdemir F, Tellaloglu S. Microsurgical inguinal varicocele repair in azoospermic men. Urology. 2001;57:328-33.

69. Pasqualotto FF, Sobreiro BP, Hallak J, Pasqualotto EB, Lucon AM. Induction of spermatogenesis in azoospermic men after varicocelectomy repair: an update. Fertility and sterility. 2006;85:635-9.

70. Palermo G, Joris H, Devroey P, Van Steirteghem AC. Pregnancies after intracytoplasmic injection of single spermatozoon into an oocyte. Lancet. 1992;340:17-8.

71. Aboulghar MA, Mansour RT, Serour GI, Fahmy I, Kamal A, Tawab NA, et al. Fertilization and pregnancy rates after intracytoplasmic sperm injection using ejaculate semen and surgically retrieved sperm. Fertility and sterility. 1997;68(1):108-11.

72. Pellicer A, Simon C, Remohi J. Effects of aging on the female reproductive system. Hum Reprod. 1995;10 Suppl 2:77-83.
73. Rowe T. Fertility and a woman's age. J Reprod Med. 2006;51:157-63.

74. Aging and infertility in women. Fertility and sterility. 2006;86 Suppl $5:$ S248-52.

75. Nieschlag E, Hertle L, Fischedick A, Abshagen K, Behre HM. Update on treatment of varicocele: counselling as effective as occlusion of the vena spermatica. Hum Reprod. 1998;13:2147-50.

76. O’Brien JH, Bowles B, Kamal KM, Jarvi K, Zini A. Microsurgical varicocelectomy for infertile couples with advanced female age: natural history in the era of ART. J Androl. 2004;25:939-43.

77. Sharlip ID, Jarow JP, Belker AM, Lipshultz LI, Sigman M, Thomas AJ, et al. Best practice policies for male infertility. Fertility and sterility. 2002;77(5):873-82.

78. Sautter T, Sulser T, Suter S, Gretener H, Hauri D. Treatment of varicocele: a prospective randomized comparison of laparoscopy versus antegrade sclerotherapy. Eur Urol. 2002;41:398-400.

79. Bahren W, Lenz M, Porst H, Wierschin W. [Side effects, complications and contraindications for percutaneous sclerotherapy of the internal spermatic vein in the treatment of idiopathic varicocele]. Rofo. $1983 ; 138: 172-9$

80. Matthews RD, Roberts J, Walker WA, Sands JP. Migration of intravascular balloon after percutaneous embolotherapy of varicocele. Urology. 1992;39:373-5.

81. Fretz PC, Sandlow JI. Varicocele: current concepts in pathophysiology, diagnosis, and treatment. Urol Clin North Am. 2002;29:921-37.

82. Ivanissevich O. Left varicocele due to reflux; experience with 4,470 operative cases in forty-two years. J Int Coll Surg. 1960;34:742-55.

83. Goldstein M, Gilbert BR, Dicker AP, Dwosh J, Gnecco C. Microsurgical inguinal varicocelectomy with delivery of the testis: an artery and lymphatic sparing technique. The Journal of urology. 1992;148:1808-11.

84. Cayan S, Kadioglu TC, Tefekli A, Kadioglu A, Tellaloglu S. Comparison of results and complications of high ligation surgery and microsurgical high inguinal varicocelectomy in the treatment of varicocele. Urology. 2000;55:750-4.

85. Ficarra V, Cerruto MA, Liguori G, Mazzoni G, Minucci S, Tracia A, et al. Treatment of varicocele in subfertile men: The Cochrane Review--a contrary opinion. Eur Urol. 2006;49(2):258-63.

86. Benoff S, Gilbert BR. Varicocele and male infertility: part I. Preface. Hum Reprod Update. 2001;7:47-54.

87. Evers JL, Collins JA. Assessment of efficacy of varicocele repair for male subfertility: a systematic review. Lancet. 2003;361:1849-52.

88. Madgar I, Weissenberg R, Lunenfeld B, Karasik A, Goldwasser B Controlled trial of high spermatic vein ligation for varicocele in infertile men. Fertility and sterility. 1995;63:120-4.

89. Agarwal A, Deepinder F, Cocuzza M, Agarwal R, Short RA, Sabanegh E, et al. Efficacy of Varicocelectomy in Improving Semen Parameters: New Meta-analytical Approach. Urology. 2007;70:532-8.

90. Marmar JL, Agarwal A, Prabakaran S, Agarwal R, Short RA, Benoff $\mathrm{S}$, et al. Reassessing the value of varicocelectomy as a treatment for male subfertility with a new meta-analysis. Fertility and sterility. 2007; 88:639-48. 